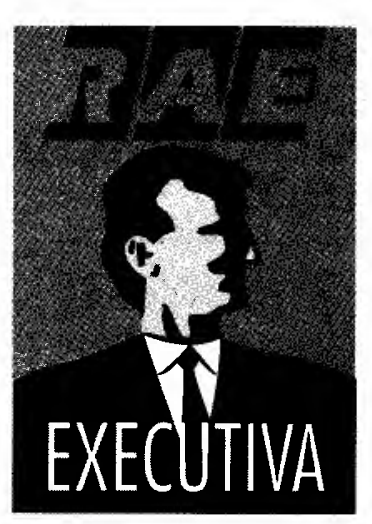

\title{
A ISO 9000 E OUTRAS EXIGÊNCIAS DA MAIOR POTÊNCIA ECONÔMICA DO MUNDO
}

* Francesco De Clcco

Exigências de certificação, normas obrigatórias, selo de conformidade da Comunidade Européia e suas novas regulamentações restritivas sobre sistemas de gerenciamento da qualidade e ambiental.

Certification, compulsory standards, CE mark and the new European's tighter regulations on quality and environmental management systems.

PALAVRAS-CHAVE:

ISO 9000, sistemas de gerenciamento da qualidade, normas, gerenciamento ambiental, selo de conformidade.

\section{KEY WORDS:}

ISO 9000, quality management systems, standards, environmental management, CE mark.

\footnotetext{
* Engenheiro com especialização no exterior em Total Loss Control e Diretor-Executivo do QSP-Centro Brasileiro da Qualidade, Seguranca e Produttvidade e do CLUBE DA 1509000.
}

No dia $1^{\circ}$ de janeiro de 1993, o Tratado sobre a União Européia, ou, como é mais conhecido, o Tratado de Maastricht de 1992, tornou-se

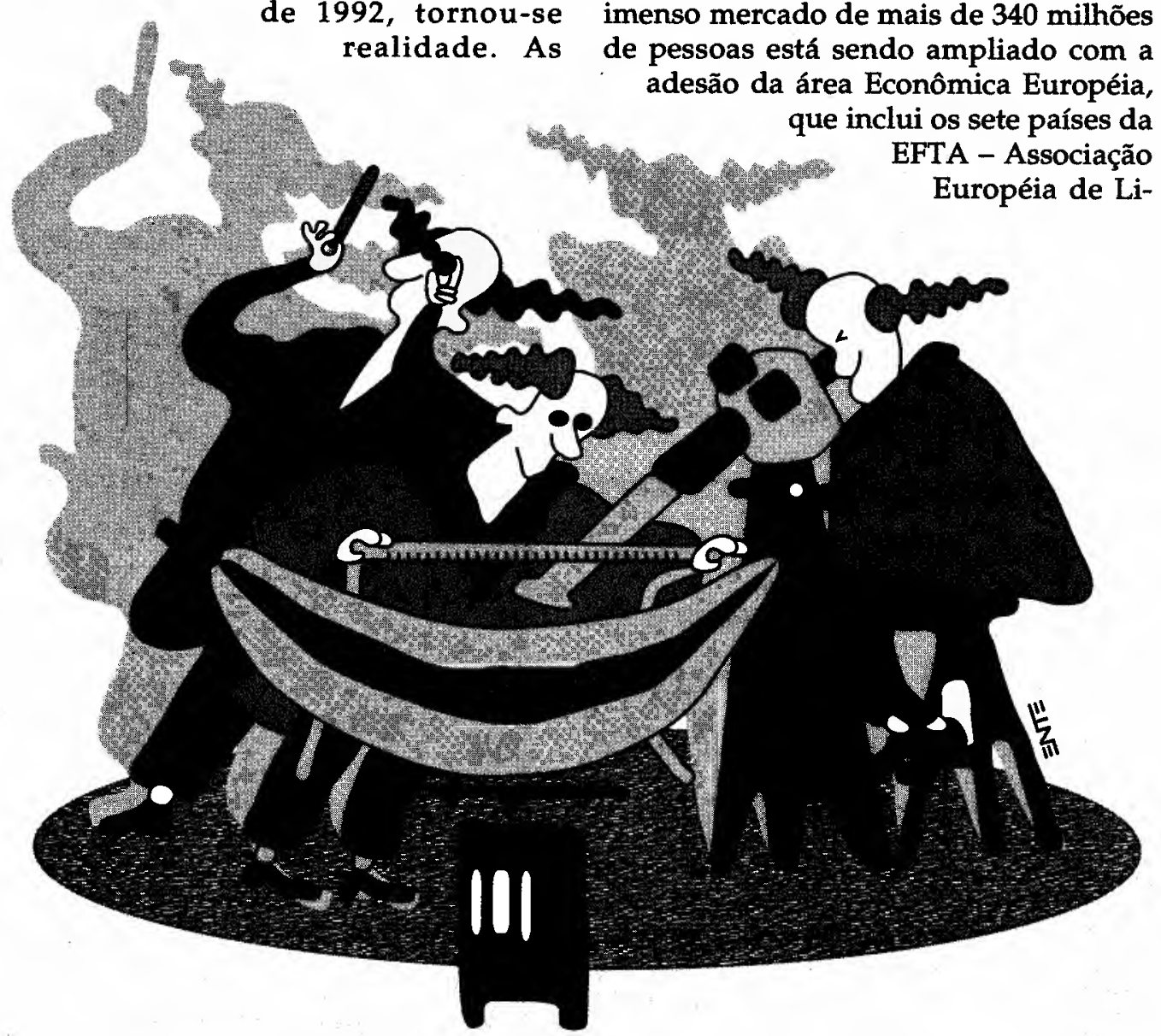

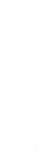

fronteiras internas entre os doze paísesmembros da União foram dissolvidas, $\mathrm{e}$ foi estabelecido um mercado único. Esse imenso mercado de mais de 340 milhões de pessoas está sendo ampliado com a área Econômica Européia ui os sete países da TA - Associação 
vre Comércio - e seus 32 milhões de consumidores. $\mathrm{O}$ acordo com a EFTA é praticamente tão abrangente quanto as regras governamentais para o mercado único. A EFTA reúne os seguintes países: Suíça, Suécia, Áustria, Noruega, Finlândia, Islândia e Lichtenstein.

A União Européia, com esse enorme mercado livre de quase $\mathbf{4 0 0}$ milhões de pessoas, e abrigando várias nações-líderes, poderá agora tornar-se a maior potência econômica do mundo.

O Tratado de Maastricht representa o que a própria Comunidade representa: uma boa idéia, uma etapa do processo de integração européia, que teve início com a criação do Mercado Comum. $O$ tratado reafirma o objetivo de facilitar a livre movimentação de pessoas, e expressa a determinação de promover o progresso econômico e social para todas as pessoas da União, dentro do contexto do mercado interno, isto é, do mercado único, e "da coesão reforçada e da proteção do meio ambiente". Estas últimas palavras, mais do que quaisquer outras, ilustram os dois aspectos da União que aqui mais nos interessam: as oportunidades, que se traduzem na coesão, e as regulamentações, que dizem respeito às questões ambientais.

O mercado interno europeu consiste de oportunidades e regulamentações. Pode-se descrevê-lo como um maravilhoso novo mundo de liberdade, onde as fronteiras e os postos de alfândega estão sendo eliminados, mas onde proliferam regulamentações, especialmente as que tratam de saúde, segurança, meio ambiente, direitos dos trabalhadores, responsabilidade pelo produto e certificação. Há liberdade se se permanecer fora dos negócios, e particularmente se não se fabricar nem distribuir mercadorias.

Para os fins deste artigo, o elemento mais significativo da União é a Comunidade Européia (o artigo 6 do Tratado finalmente alterou o nome de Comunidade Econômica Européia - CEE para Comunidade Européia - CE).

Como regra geral, o mais importante a ser considerado pelas empresas, tanto brasileiras como de outros países que têm negócios com a $\mathrm{CE}$, é que as normas para seus produtos e para seus sistemas de gerenciamento, como as de qualidade, agora, e as de proteção ambiental, brevemente, devem adequar-se às exigências européias.

Para se provar que um produto atende a determinadas normas, geralmente, deve-se demonstrar que existe um sistema aceitável e harmônico de gerenciamento da qualidade. A norma de gerenciamento da qualidade adotada pela $\mathrm{CE}$ é a ISO 9000, que corresponde à norma européia EN 29000.

A regulamentação que está sinalizando o início de exigências ambientais é a chamada Eco-Auditoria. Ela é compulsória para os países da $\mathrm{CE}$, desde $1^{\circ}$ de janeiro de 1993, para que criem organis-

\section{Praticamente todas as} corporações multinacionais e os grandes compradores, além de órgãos públicos $e$ empresas estatais, estão exigindo de seus fornecedores o atendimento à ISO 9000.

mos oficiais regulamentadores da matéria. Para as empresas, a Eco-Auditoria é voluntária, restando ainda três anos para que se torne obrigatória.

Outro ponto importante para aqueles que estão estabelecendo relações comerciais na $C E$, ou que já têm negócios na Comunidade, é saber que as regulamentações sobre Segurança e Saúde no Trabalho, obrigatórias desde 1989, foram ampliadas em 1993 e agora estão se transformando em lei em cada país-membro, podendo representar um sério risco para as organizações que ignorarem que os trabalhadores poderão impetrar ações por danos que sofrerem, e mesmo por negligência da administração da empresa.

Os requisitos de segurança e saúde deverão ser considerados assuntos de rotina e da boa prática comercial, en- 
quanto que as exigências de clientes e de consumidores forçarão os fornecedores e distribuidores a ir cada vez mais em direção à ISO 9000 e, dentro em breve, em direção à norma de gerenciamento ambiental, sobre a qual falaremos mais adiante.

A rigor, a mais importante questão para as companhias que exportam para a Europa é saber se a CE é uma terra de prosperidade ou é um mercado fechado. A resposta é que a Europa é um mercado aberto, cheio de oportunidades, se os exportadores conhecerem o que está acontecendo com o processo de normatização.

A boa notícia é que esse processo, embora impulsionado pela $\mathrm{CE}$, é mundial, promovido e coordenado por organismos como a International Organization for Standardization (ISO), com sede em Genebra, e a International Electrotechnical Commission (IEC).

A ISO é uma organização constituída por organismos nacionais de normatização de 94 países. O Brasil é representado na ISO pela $A B N T$ Associação Brasileira de Normas Técnicas. A ISO promove o desenvolvimento da normatização para facilitar o comércio internacional, e para fomentar a cooperação no processo de elaboração das normas. Ela publica normas internacionais em todos os campos, exceto na área de engenharia elétrica e eletrônica, a qual é de responsabilidade de sua co-irmã, a IEC.

Dentro da Europa, os organismos de normatização são:

- as entidades nacionais de cada paísmembro da CE, como o BSI (Inglaterra), DIN (Alemanha), AFNOR (França), NSAI (Irlanda);

- os comitês nacionais eletrotécnicos, como o BEC (Inglaterra), DKE (Alemanha), ETCI (Irlanda);

- o CEN/CENELEC, o Instituto de Normas Unificadas, que cria as normas para a CE;

- o ETSI, Instituto Europeu de Normas de Telecomunicações.
Os países não-europeus têm acesso a ISO/IEC, que desenvolve seus trabalhos em estreita sintonia com o CEN/CENELEC, e vice-versa. Só que, no momento, um bom número de normas européias está liderando o processo, o que implica que uma norma européia (EN) pode perfeitamente ser mais avançada que uma norma internacional.

Portanto, a primeira consideração a ser feita para qualquer produto direcionado à Europa é que ele deve atender aos requisitos da respectiva norma internacional, se existir essa norma para o produto a ser exportado. Se existir uma norma européia, que pode também ter uma equivalente internacional, os detalhes técnicos deverão ser obtidos da própria EN.

Se o produto estiver numa categoria coberta por uma diretiva da CE (diretriz de legislação para os países-membros), como é o caso de máqui n a s, brinquedos, materiais de construção, a parelhos elétricos, médicos e a gás, todos os requisitos da diretiva deverão ser cumpridos. Nesse caso, o produto deverá ser certificado e deverá ostentar o CE mark (selo de conformidade), para garantir sua livre circulação dentro da Comunidade.

Por uma série de motivos, uma empresa pode necessitar implementar um sistema de gerenciamento da qualidade baseado na ISO 9000 . Muitos organismos europeus de certificação estão agora insistindo na ISO 9000, antes de certificar determinados produtos, mesmo aqueles cobertos por diretivas. Praticamente todas as corporações multinacionais e os grandes compradores, além de órgãos públicos e empresas estatais, estão exigindo de seus fornecedores o atendimento à ISO 9000 . 
Tudo isso, porém, nẩo será suficiente para aquelas organizações que querem incrementar as avaliações de seus fornecedores e dos materiais por elas adquiridos.

No momento em que escrevemos este artigo, tanto a regulamentação do esquema de Eco-Auditoria, da Comunidade Européia, como a BS 7750, a norma inglesa de gerenciamento ambiental, estão chegando com força total. Mesmo antes do aparecimento delas, algumas companhias já estavam exigindo de seus fornecedores que demonstrassem conformidade com as boas práticas ambientais.

A norma BS 7750 é um mecanismo que permite garantir, através de um organismo certificador credenciado, que as regulamentações ambientais estão sendo atendidas. Ela será adotada por organizações que estão procurando ir além da ISO 9000, ou por empresas que já estão sendo pressionadas a produzir evidências sobre sua atuação em relação à proteção do meio ambiente.

É praticamente certo que uma norma ISO "verde" será lançada, tendo por base a BS 7750 . Supõe-se que isso acontecerá no segundo semestre de 1994, quando estiver em pleno funcionamento o esquema de Eco-Auditoria da CE.

É importante observar que a ISO 9000 trata, principalmente, do controle das várias fases do ciclo de vida do produto, enquanto a BS 7750 trata das questões ambientais relacionadas ao projeto do produto, ao processo produtivo, e ao uso e disposição final do produto, incluindo sua embalagem. Ela também aborda aspectos relativos à segurança e à saúde dos trabalhadores, e a procedimentos de emergência em caso de acidentes (segurança da comunidade).

Todos os sinais indicam que os processos que mencionamos ao longo deste artigo crescerão na segunda metade da atual década, isto é, exportadores para a Europa e fornecedores locais serão cada vez mais solicitados a comprovar que seus produtos atendem, além dos requisitos de qualidade, aos requisitos da norma ambiental ou da Eco-Auditoria, ou de ambas.

No que diz respeito especificamente às empresas exportadoras brasileiras, é fundamental, portanto, que adiram tanto às referidas normas quanto à certificação por um organismo credenciado. Além disso, em função das exigências em relação ao CE mark (para os produtos cobertos por diretivas) e da atual le-

\section{É praticamente certo que uma}

norma ISO "verde" será lançada, tendo por base a BS 7750 .

Supõe-se que isso acontecerá

no segundo semestre de 1994, quando estiver em pleno funcionamento o esquema de Eco-Auditoria da CE.

gislação européia de defesa do consumidor, as organizações de fora da Europa devem também ter, dentro da Comunidade, representantes ou revendedores autorizados, que estejam preparados para assumir integralmente a responsabilidade pelo produto, em qualquer situação, com ou sem o CE mark.

\section{BIBLIOGRAFIA}

- INTERNATIONAL ORGANIZATION FOR STANDARDIZATION (ISO). Vision 2000 - A strategy for international standards' implementation in the quality arena during the 1990s. ISO 9000 international standards for quality management. $3^{?}$ ed, Genebra.

- NATIONAL ISO 9000 SUPPORT GROUP. The environmental management standard (BS 7750) Continuous improvement. Alto, MI, p. 1-3, Sep. 1993. $\square$ 